\title{
LECTURAS DE UN DESENCUENTRO: LAS FORMAS DE LA VIDA SOCIAL EN RADIOGRAFÍA DE LA PAMPA DE EZEQUIEL MARTÍNEZ ESTRADA ${ }^{1}$
}

\author{
¿Y no ocurrirá otro tanto con la democracia? \\ ¿No será, pues, el deseo insaciable de su propio \\ bien lo que ocasiona su perdición? \\ Platón, La República, Libro VIII
}

Palabras clave: ensayo de interpretación nacional, Martínez Estrada, historia, política

\section{Introducción}

Cuando nos acercamos a Radiografía de la Pampa el género no nos parece traer dificultades, es un ensayo y esto nos parece natural porque está escrito por un ensayista; si leemos cualquier entrada sobre su autor en los diccionarios biográficos, enciclopédicos o filosóficos encontramos contundentes definiciones: «escritor y ensayista ...». Pero Martínez Estrada no es sólo un ensayista, su obra trascendió ampliamente el género.

Los pormenores del acceso a los círculos culturales porteños para el autodidacta hijo de un almacenero de provincia no nos importan aquí, más bien cabe recordar que su entrada en el mundo de las letras argentinas fue por la puerta grande de la poesía y no por su ensayística. Bajo los auspicios de Leopoldo Lugones, la irrupción de Martínez Estrada en el centro de la escena cultural del momento lo ubicaba como el sucesor natural del entonces máximo poeta nacional. Sin embargo, él mismo se fue deslizando hacia los márgenes, para lo que la elección del género de producción se convertiría en una herramienta determinante. El primer corte abrupto es con la publicación, en 1932, de Radiografía de la Pampa, cuando pasa de la poesía al ensayo; a partir de allí transitó por las letras utilizando el género como un arma semántica más: quiso decir ciertas cosas cuando se expresó en verso, otras cuando usó el ensayo y otras muy distintas cuando manejó el cuento, la caricatura o hasta la novela.

Punto de inflexión de obra y vida, es utilizada por su autor para plantear una suerte de filosofía de la sociedad argentina, para lo que se vale de una particular lectura de la historia. Radiografía de la Pampa tiene el ritmo de un relato mítico que tiene el objetivo de desmitificar. Historia social donde la narrativa épica de la conquista es subvertida, donde las instituciones son sólo miradas de soslayo, donde los héroes no tallan sino que las

Este artículo es una reformulación del trabajo presentado para el seminario de posgrado sobre Historiografía, dictado por el Dr. Fernando Devoto en el marco del Doctorado en Historia (Universidad Nacional del Centro, Tandil). Agradezco su generosa y penetrante lectura, así como también la cálida experiencia compartida con los colegas participantes del curso durante las jornadas de lectura y debate. 
pasiones más bajas de hombres comunes los llenan de frustraciones y derrotas. Aquí nos encontramos, en un largo registro descriptivo, con conquistadores conquistados, aventureros desengañados, pioneros detenidos; y sobre todo, con la soledad.

\section{Ecos de la tierra}

Trapalanda, la tierra del oro, el paraíso en la tierra; América: una trampa. La decepción llega a desesperar al español que, reo o ambicioso, había cruzado el mar para conquistar, saquear y dominar, sufre el desengaño. La quimera de la riqueza rápida se deshace, y para aquel hombre para el que robar era más honorable que trabajar la tierra no tiene un valor propio sino como herramienta de la política y la pertenencia. Importado de la península el concepto de ciudadanía ateniense, se da ciudadanía al propietario sobre el que trabaja. Solamente así, como bien inerte, la tierra yerma pasará a tener un valor: allí el propietario fantaseará proyectando construcciones futuras, ella servirá como garantía hipotecaria, será el trofeo, el botín del saqueo al indio. Cuando asuma que el baldío no es poder ni riqueza por si sola, verá que ya no tiene más que poblar, y allí es cuando la propiedad, que ya le había dado ciudadanía, le certificará capacidad de mando. El que queda varado en América sólo tiene dos opciones, considerarse «... elegido por Dios para algún fin excelso en la religión o la administración» o bien trabajar para modificar ese mundo nuevo e inculto. Al tomar esa segunda opción es cuando el europeo comienza a retroceder, a caminar para atrás, a transitar el camino que lo convierte en instrumento del desierto.

Sin verlo, sin planearlo, el conquistador estaba quedando atrapado por «... la fuerza más lenta pero infinitamente más grande de la naturaleza». ${ }^{2}$ Esta es la lógica principal del libro: la avasallante soberbia de la voluntad del hombre que hace pié, usa, domina y transforma hasta reconocerse en su derrota, perpleja buscando cuándo comenzó a estar dominada por poderes antiguos e inmóviles, estupefacta viendo que todo había comenzado a su propia llegada.

A partir de ese concepto la lógica argumentativa se repite mientras los participantes se suceden. Cuando la naturaleza enseña al europeo a labrar otra riqueza, al conquistador lo sigue el colono, con las mismas premisas, aunque más sórdido, «... esperando menos», y con el mismo destino. Busca dinero, busca poseer; mira su relación con el medio igual que el conquistador: busca el botín. Igual que su predecesor, evitó fijarse a un sitio, siguiendo al ganado cimarrón, fuente de su riqueza. Esa misma riqueza envilece al colono, lo barbariza. En lugar de ostentar sus hectáreas y su hacienda, las esconde, avaro y poniendo cara de distraído. Martínez Estrada describe una metamorfosis del colono hacia el pioneer norteamericano que describe Turner, incluso utilizando sin traducir el término, pero en un sentido inverso: enriquecido por la buena cosecha y embrutecido por la intemperie, se abre camino por la ciudad como avanzada de la barbarie, va introduciendo los valores del tosco en la civilización. Los más no hacían fortuna. El mito roto de la riqueza fácil los había descorazonado. Repetirían la condición del conquistador pobre «... en su

2 Todas las referencias del artículo pertenecen al texto analizado, Radiografía de la Pampa de Ezequiel Martínez Estrada, por la edición de Losada, Buenos Aires, 1991. 
harén de indias inmundas». Pasarían a ser instrumentos del desierto. Un rancho con algunas cabezas en una tierra arrendada serían su deseo dorado.

Porque la tierra tenía el tesoro escondido de la tierra baldía: la fecundidad. La primera, la más evidente, la tenía el salvaje. Arrebatarle el ganado al indio era más fácil que criarlo. El consorcio con el indio se sellaría desde el arribo mismo del español, cuando ambos se promiscuaran en su mutua soledad. A través de esa dialéctica, el blanco devendría en ganadero.

Este camino es el que describe el autor como la victoria de la tierra vencida. El medio físico había impuesto sus condiciones al conquistador. El hijo de la Europa del siglo XVI se había obligado a someterse a la industria del primitivo y había pasado a proveer al suelo europeo del que se había alejado. Los que más rápido se habían sometido eran los que tenían razón; y, si la labranza había repugnado al español por idiosincrasia desde la península, sobre el caballo sentiría la libertad y daría fisonomía a la Argentina pecuaria.

El descendiente de ese hombre vencido sería la denuncia de su derrota. El mestizo, más indio que español, permanecería más cerca de la naturaleza que de la civilización. Producto de una humillación original, era el hijo bastardo de los señores con las indias. La situación de la mujer es otro tema recurrente en nuestra obra: un botín más de ese afán de conquista, la mujer salvaje sería tratada como una posesión más dentro de la cosmovisión del blanco. Silenciosa en su rol de hembra cuando juguete nocturno del blanco, de día quedaba relegada a los trabajos pesados y la cría. La mancebía y la prostitución no son tratados por Martínez Estrada sólo como un problema social, son, ante todo, una aberración cultural. Degradadas, con menos de humanas que de bestias, sus destinos con el europeo eran secuencias de violentos raptos, cautiverios en todo iguales a la esclavitud hasta que el hartazgo del blanco terminaba en repudio. Abandonadas con sus proles, la vuelta a las tolderías les reservaba el escarnio y la muerte.

Pero, repitiendo la misma lógica, la mujer también humillaría al varón. Siguiendo a los ejércitos, fue tropa, lo curó y asistió; condicionó la libertad del soldado, lo obligó a postergar, por el calor de lo urgente, las ansias de conquista desmesurada; lo incitó a conformarse con mezquindades, desvió la angurria hacia las vísceras y lo convirtió en un ave de rapiña. Se convirtió en una pesada mochila para cargar.

No podía ser sino bastarda esta unión, ya que nada podía establecerse entre el blanco y el indio. «Entre el poderoso y el oprimido no hay pactos duraderos; una parte puede cumplir o relevarse del compromiso; la otra, está sometida por su propia inferioridad.» Sólo el recelo sería, con el tiempo la herramienta que protegería al indio; la suspicacia sería la reacción natural de la víctima del engaño; el rencor vívido, la del débil herido a traición. Animalizado desde su sangre, el mestizo preservaría las cicatrices de los golpes de sus abuelos, de la humillación de su madre. Se repetiría hacia los hijos bastardos del blanco el desprecio que se había instalado por los indios: se los consideraría españoles, pero se los excluiría de las prebendas y los puestos, sólo podrían caminar erguidos cuando fueran la carne de los ejércitos conquistadores, cuando la desheredad fuera definitiva y se vieran como salvajes asolando, en nombre del opresor a sus iguales. 
Es éste el sustrato que hace que nuestro autor vea cómo la independencia, tesis de doctores de la capital, desataría las ataduras de la bravura, cómo toda esa furia contenida conduciría al salvajismo y la anarquía. Lo que había empezado como un debate por la renta del puerto y por la administración despierta en el mestizaje la conciencia de esa inferioridad a que estaba sometido; tan sometido estaba que no es la independencia un tema que interese en el campo, sino que allí se desborda la puerta que abrieran desde la ciudad. La tesis triunfaría sobre la realidad recién en 1853.

Y la realidad ofrecía otro panorama, muy diverso. Las pampas no eran desiertos, pero tampoco eran estados; allí no hay gobiernos, lo más parecido es la autoridad, que se cuenta según el grueso de los ejércitos, y es mudable. El caudillo, más parecido al bandido que al señor feudal, es la carnadura de esa realidad mientras que, a la vez, es otro derrotado por el medio: en lugar de generales que impongan su ley entre la turba, la autoridad la ejercen caudillos que asumen la ley de la turba. Y la ley se impone a punta de cuchillo.

La herramienta de faena ganadera se convierte en el instrumento de la política. Cita Martínez Estrada a Mansilla: «Los unitarios mandaban castrar, los federales degollaban.» En todo caso otra vez el medio se impone cuando la práctica del trabajo diario se convierte en la de la guerra: «De la nueva esclavitud podría erigirse como símbolo, la espada con que ganó su pan y la herramienta con que salvó su vida.»

\section{Pioneros de la tierra}

Es constante en adelante la repetición del mecanismo que hasta aquí venimos relatando. Radiografía de la pampa retoma la descripción de los medios físicos y su incidencia en los habitantes, aunque, a medida que avanza en el tiempo, la apelación a la herencia es una de las claves argumentales principales. Por eso es que cuando cambia la escala, la estructura es la misma. Todos los relatos provienen de aquella humillación original de la mujer aborigen raptada, esclavizada y repudiada que, victoriosa al fin por su fertilidad como la de las pampas, posterga su venganza hacia la posteridad. El poblador de las pampas haría brotar la barbarie desde su sangre hacia la sociedad toda; su rasgo psíquico, como el de la sociedad que configuraría sería la soledad.

Porque la soledad es el rasgo físico de la pampa. La nada sólo se corta por algún ombú, solitario y que sólo da sombra. Desde la verde línea del horizonte, diminuto en perspectiva, surge un pueblo entre la soledad que sólo sirve para avituallar a los campesinos. Es, seguramente, igual al pueblo anterior y al próximo que el caminante encuentre. La rutina hace que parezca una tumba para los vivos, muy parecida a la tumba de los muertos. Físicamente todas las ciudades se parecen a Buenos Aires, pero más chico y más viejo, aún si cincuenta años es demasiada edad para muchas de ellas. Cada una tiene su sociedad: aristócratas de abolengo, que tienen fincas, participan de la política, las calles y los edificios llevan sus nombres y miran con respeto a la plebe que no los respeta ni los envidia. En esos lugares la inteligencia sólo puede ser un estorbo, el único camino que le queda es el de la migración hacia la metrópoli.

En estos pueblos, donde los pionners por elección o por renuncia decidieron hacer alto, la sociabilidad se juega en un movimiento pendular que va desde la protección de 
la propia privacidad hacia la invasión de la ajena. Inquiere con amortiguada curiosidad pero elude la pregunta. El guapo es el personaje característico de estos lugares, la soledad vuelve a ser el patrón. Unigénito del gaucho malo, una lógica masculina gobierna su persona. Fuera de la corriente, el sentido gregario de la vida es algo desconocido para él, es una fuerza del campo que circula por los pueblos chicos. Solitario, sus hazañas no son premeditadas ni pretenden dejar huella: toda su masculinidad desborda de su cuerpo y alivia sus impulsos por medio del arrebato, a la saciedad tampoco la conoce, como no conoce a la necesidad. Así, pobre como es, dispone de crédito del que no abusa y, eventualmente, regentea una mujer a la que no cobra en especie, sólo cubre los vicios. Su maldad es estado de naturaleza y su valor entraña una condición de virilidad.

Para Martínez Estrada estos personajes son exponentes del tipo de sociedad del que surgen. El guapo es el elemento antisocial en una sociedad mal constituida o constituida con descontento. Representa los sentimientos reprimidos de esa sociedad, y eso es lo que hace que se llegue a tolerar con cierta simpatía a estos prófugos que no son perseguidos. No alardea de sus muertos ni llega a burocratizar el temor que genera como sí llegan a hacerlo en las ciudades los compadres; sin embargo, los poderes locales no lo persiguen, no dejan de ser funcionales y eventualmente útiles.

El ganado ha sido también el hacedor de fortunas. Pero nada de lo que logra el habitante de la pampa lo satisface. A medida que acumula dinero, honores, reconocimiento ... sigue una parte de su deseo inmersa en el vacío; sólo la acumulación, la multiplicación de lo que sí está a su alcance podrá atemperar ese vacío, nunca llenarlo porque el migrante llega sin pasado, pero también sin destino, y el destino no se llena con dinero. A la soledad de estas inhóspitas regiones, sólo se llega de la nada, y lo que se logra se vuelve un cepo que fija al hombre a la pampa. Solo la política tiene aquí su sentido total y vital, inflama los ánimos y libera la bestia embozada. La violencia es algo cotidiano sólo de esta manera se la puede encauzar y darle un sentido: las rivalidades pueden ser ásperas, pero por rivalidad se obtienen logros que la solidaridad nunca alcanzaría.

A medida que nos alejamos del centro, estos mundos cobran más autonomía, y también la soledad. En la Patagonia, zona inhóspita, el hombre, de asentamiento más reciente, desata con mayor furia su barbarie y se apega más fervientemente a los vicios. La pobreza aislada es doble pobreza.

La tierra y su fertilidad fue también el centro de la historia de las pampas para nuestro autor. El ganado fue el tendón de las guerras civiles, el esqueleto de la nación y la piedra de escándalo de las gestiones. La lectura del manejo de los gobiernos como el manejo de estancias no es novedosa, pero hacer de la historia argentina una historia de las vacas resulta un hilarante ejemplo para pensar esa lectura: los tratados se han pagado con vacas, por vacas se combatió al indio y por las vacas se corrió la frontera. Una sociedad en torno a esos animales reproducía la práctica del rebaño. El caudillo se convertía en una suerte de líder místico, y su capacidad para conducir a los ejércitos de pastores hacia el maná del ganado pasaba a ser una de sus mejores virtudes. Las herramientas para estos fines eran el baquiano y el rastreador; con más de rabdomante el primero y más de detective el 
segundo, fueron los canales de las victorias de los ejércitos y en sus manos se depositó la fortuna de más de un general.

Solo mediante el derramamiento de sangre y el saqueo se alcanzaría la conciencia nacional. Las levas de gauchos en chiripá fueron hechas a punta de bayoneta. A veces con un simple distintivo, a falta de uniforme, se iban identificando como miembros de un mismo grupo. Como el verdadero combate es en los campos, al hombre de iniciativa sólo le quedaba el camino de las armas, por ello es que las milicias se nutrieron de los hombres mejor preparados. «Los ejércitos suramericanos se formaron antes que el pueblo suramericano [...]» Para Martínez Estrada, la intromisión de los ejércitos en el gobierno no es tanto un acto de fuerza del ejército sino de debilidad de los gobiernos: «[...] sólo hay que levantar la película cívica para que aflore el armazón metálico de la estructura militar.» Es esta debilidad crónica de la civilidad el pecado original de las revoluciones latinoamericanas.

\section{Arte, fiesta, política}

En esta hipótesis nos encontramos con uno de los meollos de Radiografía de la Pampa. Martínez Estrada se oponía con convicción al golpe de estado de 1930, y el libro surge de las cavilaciones que este proceso produjo en su autor. Vemos entonces cómo el profundo análisis de un espacio, de una cultura, de una sociedad, se vuelca también hacia la política.

Damos sentido ahora a esta vocación por clasificar y caracterizar a los personajes de las pampas, de los pueblos, de las ciudades. «Desde donde concluye el guapo hasta donde comienza el guarango, hay la octava del compadre.» Saltan a la vista las raíces que nuestro autor halla en este personaje: ya lo ha leído en Hudson, hecho un mozuelo que baja al río a desafiar a las lavanderas. Es pobre, pero por linaje debe mantenerse así para mantener su razón de ser; no es antisocial, tal vez sólo haya falta de coordinación entre los tiempos de éste individuo y los de la sociedad. Sin una lectura pormenorizada, capta el destiempo en que se mueve, y busca aparejarse con la vanguardia de la sociedad mientras atrae a sí, con cierta pose indolente, lo que necesita del mundo exterior.

Otro elemento inmóvil en esta caracterización de la sociedad, es aquello que nuestro autor denomina fuerzas psíquicas: amor, fe, idioma. Aquí también aparece clara la tan mentada filosofía de la historia argentina que se atribuye a Radiografía de la Pampa. No existe aquí solución de continuidad entre 1830 y 1930: la unidad de estilo de un pueblo, el hueso, la unidad del relato superficial de los episodios está dada por la inmanencia de estas cuestiones abstractas. Y la inmanencia está dada por la pérdida, en Trapalanda, del significado original de las cosas. El progreso aquí no existe, más allá del telégrafo o el ferrocarril, no son los nuevos tiempos una etapa superior a los anteriores. «La grandeza o decadencia de un pueblo cuentan por otros datos que por la expansión mecánica de la riqueza.»

El crecimiento desproporcionado de Buenos Aires en detrimento del resto del país no significa sólo un problema de planificación urbana, es un problema moral porque hace dependiente, pobre y lejano el resto del país. Civilización no es la acumulación material 
sino la utilización de los bienes, y la civilización no alcanza las afueras de la capital porque es una condición necesaria para su preponderancia. Las formas políticas de la rivalidad y la asonada han sido las herramientas de esa preponderancia, la herramienta de sometimiento ha sido el ejército; es lógico entonces que esas formas políticas se extiendan, una vez más desde la barbarie, hasta el gobierno nacional. Si en todo el país la única autoridad y expresión de orden son los generales por qué escaparía la capital a tales lógicas.

Nada se consolida en América como se supone que era un principio, no el amor, no la fe; en fin, el idioma tampoco. El sentimiento del romance, la virtud de folletín nunca existió aquí; en lugar de ello, la sumisión de la mujer maltratada, vejada, juguete nocturno del conquistador en la humillación originaria, es una solapada forma de venganza. El dogma de la única, católica y apostólica Iglesia romana también llegó con orgullo para imponerse, pero en lugar de ello sólo se encontró con su descomposición, su deformación, su adaptación a un idioma bárbaro de seres semidesnudos de alma dudosa; sólo podría, así, repetirse hasta el paroxismo la imponencia de las formas externas del rito y las manifestaciones físicas del culto; templos magníficos atesorarían riquezas exorbitantes que sólo servirían para atraer saqueadores, ningún responso podría hallar allí el alma triste. Sorprende el caso del lenguaje: si cada región de Europa generó su lengua acorde a su paisaje y sus costumbres, si el conquistador trajo sustantivos que requirieron analogías muchas veces forzadas para adaptarse a lo que encontró, resulta curiosa la relativa integridad que llegó a conservar el idioma en regiones tan apartadas y diversas; sin embargo multitud de giros han muerto bajo el peso del desuso. Por lo demás, para Martínez Estrada, el lenguaje no es un instrumento de la razón sino un órgano del sentimiento: no se habla según se piensa sino según se siente, y los estilo sí que se adaptan al medio; en esta línea, el hablar tosco y rudo es una consecuencia de la tosquedad y rudeza de la vida. Es, además, una expresión del resentimiento, una forma de resistencia, otro arma parricida.

Cuando la independencia, dejó de existir la dualidad entre España y las colonias y fue reemplazada por otra: Buenos Aires y el interior. Argirópolis se debatiría en adelante entre quedar fuera de todos los pactos o incluir dentro de sí al resto del territorio. A partir de la resolución de esta disyuntiva la política nacional sería tratada como si fuera política municipal, y como si se tratara de un caserío rodeado de algunos terrenos baldíos que tratados en conjunto se llamarían interior, y uno por uno sería tratados como provincias. Por su parte, las provincias han tratado a la capital como una metrópoli, con objetivos nacionales distintos y hasta opuestos.

Terminadas las guerras de emancipación, en Buenos Aires se refugiaron los residuos de la reacción, y establecieron con las provincias una distancia que no se mide en millas pero que resulta más contundente, más absoluta: la que separa al centro de la periferia. A partir de allí, Europa pasó a estar más cerca de Argirópolis que cualquier pueblo del interior, y la ciudad se pareció cada vez más a cualquier gran capital: rica, cosmopolita y con un destino promisorio, como París o New York. Sin embargo, en el llano de sus calles, en su sangre y su estilo, se parece más a cualquier pueblo olvidado de San Luis, Jujuy o Catamarca; «es la capital federal de la República Argentina». 
La población se amontona en aquel paisaje monótono, aquella pampa edificada donde el techo es igual al piso, aquella ciudad que, como cualquier curso de agua, transita desde el corazón de la planicie hacia el Atlántico. Entrar en una casa, atravesar una puerta, es trasladase de un mundo a otro, donde lo diverso cobra vida. Porque el propietario de un casa pasa a ser un ente jurídico que alquila o desaloja según le viene en conveniencia. El ímpetu rentístico hace que el que alquila habitaciones tenga trabajando para sí a tantas familias como inquilinos, a los que desprecia por igual, individualmente. Porque allí no hay comunidad sino suma de individuos, celosos de su privacidad todos, invasores de la ajena cada uno. Así es la relación entre las construcciones: no hay orden, no hay lógica ni gusto general. Cada casa, sola; cada edificio se ha construido como si fuera el único; en lo único que concuerdan es en que todas las construcciones ahorran luz y aire, maximizan el espacio, siguen intentando vencer a la naturaleza; cada peso trabajado se convierte en un ladrillo para levantar un piso más sobre el techo, hasta los adornos parecen un desafío; cada casa se parece más a su propietario que al resto de la ciudad.

Los suburbios no aparecen como idea romántica o vestigios de un pasado mejor. El concepto de «ciudad indiana» sorprende por lo gráfico. Es la ciudad irregular y levantisca que aparece flotante por los bordes. Las casas pobres, se disponen como lugares de paso; no se adornan, porque puede ser repentina la decisión de abandonarla, la estrechez no permite pensar en nada superfluo ya vida relajada no se percibe por el exterior de una casa: todo es producto del esfuerzo.

Sin embargo, la conducta sigue siendo la de una aldea, una gran aldea. Aún con pobladores de a millones, volvemos a encontrar las pampas entre los adoquines. El oficinista se ve impugnado por su condición, y no existe límite entre lo civilizado y lo bárbaro. El guarango es un exponente de los arrabales, pero transita por las calles del centro de la ciudad; inimputable, representa su farsa agresiva sin poner el propio cuerpo como garantía; sólo la tolerancia de los que han aprendido a no tomarlo en serio le permite seguir transitando por las sacrosantas cuadras de la calle Florida.

Y he aquí la excepción. La calle Florida es para Martínez Estrada el lugar de la síntesis. En rigor de verdad no es una calle, es un estado de ánimo. Es el microcosmos donde se mezclan el rico y el pobre, donde siempre es domingo y donde el hombre se olvida de su condición para extrapolarse más allá. Allí se aborrece la palabra sincera, sólo vale especular; y se genera el clima para trascender en la creatividad y el pensamiento, donde se forman las utopías de las que algo al fin quedará. Sólo salir de Florida hará al pobre conciente de que su color era producto del maquillaje; sólo se recordará de cómo era cuando vuelva a la pobreza de su pieza y vuelva a encontrarse frente a frente con su propia vida.

Ni siquiera la noche ofrece en Buenos Aires esas posibilidades. Mientras los cuerpos cansados se restauran en el sueño, de las sombras emergen las almas pecadoras que con gesto adusto van a amontonarse en los cafés o los cabarets. Allí se baila y se bebe sin diversión, como se podría estar haciendo otras cosas. Las mujeres hacen de cortesanas sin gusto, y no lo ocultan; al bailar se muestran distantes, como pensando en un tiempo pretérito y más feliz, como los personajes de las letras de algún tango. Los jóvenes no parecen divertirse, se mueven como si vertieran un dejo de desprecio moral por esos lu- 
gares, de los que no se reconocen como partícipes. El que se embriaga se vuelve taciturno o hasta agresivo y hasta el que está alegre tiene una «alegría de cabaret», una alegría triste. El lugar donde el porteño va a divertirse no lo divierte. Como el tango el cabaret es triste.

Como el tango en letra, música y baile. La danza raya en su opuesto cuando se trata del tango. Movimiento sólo de la cadera hacia abajo, la rigidez del torso es la expresión de lo rutinario. Nacida como una música suburbana, lasciva y clandestina, al imponerse perdió su expresión. Sí tiene un efecto narcótico, de ensoñación, que subyace al movimiento copulativo mecánico y lejano en que se va perdiendo el cuerpo. Cuando la música termina, sólo queda en la mujer el vaho del pecado, el nebuloso resabio de los movimientos que vuelve, viscoso, a hacerse eco de la momentánea entrega que la acaba de humillar.

Invierte Martínez Estrada cuando piensa la fiesta de lo invertido: «El carnaval es la fiesta de nuestra tristeza.» Como un tratamiento psicoanalítico, cualquier pretexto sirve para que se desaten las pasiones del bajo pueblo en las calles y se desaten la guarangada y los vítores, pero sin verdadera alegría. El gozo no se quiere mostrar desnudo, y hasta se aleja de cualquier conexión con los placeres sexuales. La alegría que estalla es cruel, desesperada, hostil, sombría. Es una represalia a la seriedad de los asuntos cotidianos, al tono gris de los graves problemas corrientes, es por eso que se expresa como una venganza, a modo de estallido. Entonces los colores del disfraz se mezclan con los humores del alcohol para paliar intrínsecas necesidades de lujuria y alegría. Junto con el teatro, el carnaval hace triunfar las fuerzas sometidas de la ociedad: ocio, locura, regocijo, disparate, sensualidad; ponen sobre las tablas o las calles aquello que pudo ser y no fue. El pueblo busca invertir, aunque sea por un momento, aunque sea en la ficción del teatro o del desfile el destino esquivo que le tocó en suerte; la serpentina se tira con la puntería de la pedrada.

Como forma más cotidiana de escapar de los pesares de la vida cotidiana, nuestro autor menciona más que a la alegría, a la ensoñación. Son los momentos en que las gentes despegan de su humanidad y pasan a una irrealidad patente. El espacio de la diversión no divierte, distrae, y transporta a los individuos a otras dimensiones. Como los cabarets o el tango, lleva a lugares de ensueño el hipódromo. Allí se condena el hombre que no puede sofocar sus fuerzas interiores por otros caminos más meritorios; se transporta a la posibilidad, cabeza a cabeza, de deshacerse de sus penas en una fantasía de libertad y romántica alcurnia. Sólo cuando terminan las carreras volverá a su mundo, pero no sin el eco de la llanura golpeando su espíritu en el sonido del galope de un caballo.

Para el hijo del inmigrante la llanura no significa lo mismo, y el hombre de a pié prefiere el otro circo moderno: la cancha de fútbol. El honor tribal y de barrio se pone en juego al tomar partido por uno u otro equipo. La faceta estética del hombre que ordena su vida según la jornada laboral se canaliza por el juego del balón; no se practica como ejercicio sino como juego. La capacidad de pensar y hacer a la vez revela en los estadios la índole y la técnica de las grandes masas. «El deporte ha tomado en cada país la peculiaridad del alma colectiva. Entre nosotros el fútbol es el sur contra el norte.» 
Si podemos describir las formas de la ciudad y las alternativas del comportamiento social de sus pobladores, llegaremos a lo que Martínez Estrada define como sus dioses. «Toda manifestación colectiva de potencia es de cariz político.» Repleta como está la política de «[...] ideas sin madurar, por anhelos ilegítimos; aunque también por una inconsciente sed de justicia y de fe [...]» acumula energías que se perderían en el vacío o en la acción destructora. Como no existe un marco social claramente estructurado donde volcar el sentido de su acción, se reviste a esa dinámica del instinto colectivo de un aura mágica donde se superponen las potencias misteriosas y arbitrarias de la voluntad. El que puede descifrar las dosis de conciencia cívica en estado embrionario y puede violentar el orden de las cosas disimulando tal violencia tiene las dotes del curandero y se yergue en conductor. Ningún beneficiado (por un empleo o una concesión) podría reconocer del todo el favor, porque más lejos de lo que puede ver se encuentra el padre desconocido del logro, el político hace de comadrona, en una actividad subrepticia y profesional.

El punto de partida es el comité, que tomará sus adeptos del club, la asociación, el cenáculo o de cualquier otra comunidad corporativa. Les proveerá de una fuerza mágica que los orientará y que no habían podido adquirir en el arte, la religión, la profesión o las aulas. La nueva forma les brindará también un nombre y un líder, y un otro. El político hará los pases de magia en forma de promesas ambiguas, sacará provecho de lo que ignora y abusará de lo que sabe. Tendrá olvidos deliberados, pero podrá ostentar cifras y nombres cuando lo requiera. Su apariencia de truhán puede llevar a alguno a pensar que puede ser presa fácil, pero ahí, en esa imagen débil está su fortaleza.

Concretamente, nuestro autor define: «Nadie ha encarnado mejor que Yrigoyen la voluntad de la masa anónima.» Sólo podía caer el yirigoyenismo a manos de sus seguidores, sólo de su propio vientre podía surgir el parricida porque se fue abriendo como los brazos de un delta entre los que gobernaban para las mayorías y los que lo hacían para las minorías. Acabada expresión de la conciencia y voluntad de su pueblo, sólo podía caer Yrigoyen como el hijo sacrificado en la cruz: negado tres veces.

Si los dioses de la ciudad están en la política, el alma está en el arte. La inteligencia de las llanuras tiene como destino la persecución y el hostigamiento, su única salida es la ciudad. Allí las divinidades de la política domesticarán al espíritu libre ofreciéndole la subsistencia por sólo dos postores: el periodismo o la administración pública. Diarios, universidades y salones se encadenan en un círculo de recíprocos intereses que impedirán que el artista pueda disfrutar de su obra. Sólo puede ser peor no tener qué comer.

La madeja de los miedos se enreda, involuntaria, como una fuerza vital y social. Todo lo que se mueve sobre la tierra inerme de las pampas es inseguro, y minimizar riesgos es la ocupación principal del habitante de estas tierras. De ahí las ciudades, de ahí las opciones, de ahí los negocios; inclusive los precios de la propiedad van fluctuando de acuerdo a un estado de ánimo colectivo. Existe una supervaloración de lo propio conseguido con riesgo, de lo conseguido por la tangente de los miedos, tiene el plusvalor de la suerte; no se ha conseguido con trabajo y talento, se ha conseguido con habilidad y algo más: la semilla de la cultura rentística y especulativa. 


\section{Coda final}

En la transfiguración de las cosas que presenta Radiografía de la Pampa, decíamos, nada es lo que dice ser, o no sólo. Las formas de la vida social se deforman, pero no como si fuese su destino deformarse, sino como si nunca hubieran sido para ser lo que eran. No talla aquí ninguna fuerza mística: tan sólo el dolo que prima sobre el derecho y la razón. Es el mismo dolo para las pequeñas miserias como para los grandes proyectos que se multiplican en pequeños proyectos, pequeñamente dolosos. Son los lugares comunes de las ideas diáfanas los que proveerán alguna suerte de base sólida desde donde comenzar. Mientras que la dramática búsqueda de estabilidad e identidad se generaliza, infructuosa, a todos los aspectos de la vida. Llevar al plano de la conciencia la dualidad originaria de los argentinos es el desafío que proponía Martínez Estrada en 1932. Asumir que civilización y barbarie son lo mismo podía ser un punto de partida entonces; hoy no es siquiera un punto de llegada.

\section{BIBLIOGRAFÍA}

Altamirano, C., Sarlo, B. (1983): «Martínez Estrada: de la crítica a ‘Martín Fierro’ al ensayo sobre el ser nacional». En: Ensayos argentinos. De Sarmiento a la vanguardia. Buenos Aires: Cedal, 117-125.

Contorno, no. 4 (Buenos Aires, dic. 1955): [Número dedicado a Ezequiel Martínez Estrada].

Devoto, F., Pagano, N., Hourcade, E. (eds.) (2004): La historiografía académica y la historiografía militante en Argentina y Uruguay. Buenos Aires: Biblos.

Dido, J. C. (2004). «El ensayo y la identidad argentina». En: Espéculo. Revista de estudios literarios. Universidad Complutense de Madrid: http://www.ucm.es/info/especulo/numero27/ ensa_arg.html (4-11-2010)

Hermida, C. (2000): «Ver el esqueleto de la tierra: Radiografía de la Pampa de Ezequiel Martínez Estrada». En: Revista Celehis, 9, 12, 99-114.

Martínez Estrada, E. (1969): «Sobre radiografía de la Pampa (preguntas y respuestas)». En: Leer y escribir. http://www.ensayistas.org/filosofos/argentina/eme/eme3.htm (4-11-2010)

Martínez Estrada, E. (1991): Radiografía de la Pampa. Buenos Aires: Losada.

Prieto, A. (1969): «Martínez Estrada. El narrador y el lenguaje del mito». En: Estudios de literatura argentina. Buenos Aires: Editorial Galerna.

Rest, J. (1965): «Evocación de Martínez Estrada». En: Sur, 295, 69-72.

Rest, J. (1969): «Trayectoria de Martínez Estrada». En: Homenaje a Ezequiel Martínez Estrada. Bahía Blanca, Argentina: Universidad Nacional del Sur, 46-51.

Rodríguez Monegal, E. (1956): «Martínez Estrada o la toma de conciencia». En: El juicio de los parricidas. Buenos Aires: Editorial Deucalión.

Romero, J. L. (1947): «Martínez Estrada, un renovador de la exégesis sarmientina». Cuadernos Americanos, 33 (mayo-junio), 197-204. 
Sebreli, J. J. (1986): Martínez Estrada: una rebelión inútil. Buenos Aires: Catálogos.

Viñas, D. (1954): «La historia excluida: ubicación de Martínez Estrada». En: Contorno, 4 (Buenos Aires, diciembre 1954), 2-4.

Viñas, D. (1974): «Profecía, heterodoxia y progresismo: Martínez Estrada». En: Literatura argentina y realidad política. De Sarmiento a Cortázar. Buenos Aires: Ediciones Siglo Veinte, 92-103.

Viñas, D. (1982): «Ezequiel Martínez Estrada, hace tiempo y allá lejos». En: Cuadernos Americanos, 6, 154-172.

\section{DVOJNO BRANJE NEKEGA NESOGLASJA: OBLIKE DRUŽBENEGA ŽIVLJENJA V RENTGENU PAMPE EZEQUIELA MARTÍNEZA ESTRADE}

Ključne besede: esej o nacionalni interpretaciji, Martínez Estrada, zgodovina, politika

Avtor v članku razčlenjuje konceptualna jedra eseja Radiografía de la Pampa [Rentgen Pampe] Ezequiela Martíneza Estrade, prvič objavljenega leta 1933. Besedilo je sestavni del skupine esejev, ki interpretirajo nacionalne teme in temeljijo na delu Facundo o civilización y barbarie en las pampas argentinas [Facundo ali civilizacija in barbarstvo v argentinskih pampah] Dominga Faustina Sarmienta. Martínez Estrada ponovno prehodi zgodovino domovine od začetkov do sodobnosti in ob tem presoja epistemološke kategorije, na katerih se je gradila ta zgodovina. Še posebej se posveti znameniti Sarmientovi formuli civilizacija/barbarstvo in predlaga svoj, morda obroben pogled na odnose med zemljo, socialnimi tipi, ki jih ta ustvari, družbo in teritorijem. Tako se v Rentgenu Pampe soočimo z dvojnim branjem - branjem zgodovine in branjem pojmovanja in interpretiranja te zgodovine. 